Article

\title{
Social Innovation Design and Sustainability of Youth-Led Bamboo Craft Brand in Zhushan Township, Taiwan
}

\author{
Ying Dai ${ }^{1,2}$ and Shyh-Huei Hwang ${ }^{1, *}$ \\ 1 Graduate School of Design, National Yunlin University of Science \& Technology, Douliu 64002, Taiwan; \\ D10530022@yuntech.edu.tw \\ 2 China Celadon College, Lishui University, Lishui 323000, China \\ * Correspondence: hwangsh@gemail.yuntech.edu.tw
}

check for updates

Citation: Dai, Y.; Hwang, S.-H. Social Innovation Design and Sustainability of Youth-Led Bamboo Craft Brand in Zhushan Township, Taiwan. Sustainability 2021, 13, 9911. https://doi.org/10.3390/su13179911

Academic Editors: Santosh Jagtap and Lucia Corsini

Received: 31 July 2021

Accepted: 31 August 2021

Published: 3 September 2021

Publisher's Note: MDPI stays neutral with regard to jurisdictional claims in published maps and institutional affiliations.

Copyright: (c) 2021 by the authors. Licensee MDPI, Basel, Switzerland. This article is an open access article distributed under the terms and conditions of the Creative Commons Attribution (CC BY) license (https:// creativecommons.org/licenses/by/ $4.0 /)$.

\begin{abstract}
Various brands of bamboo crafts created by youths have emerged in Zhushan Township, Taiwan. With the special bamboo materials available in Zhushan Township as their core, these brands have created different types of social innovations through their management, design, and mechanical knowledge. The results indicate the following: (1) The youths advocate for causes such as the preservation of culture, mutually beneficial situations, sustainable local development, and environmentally friendly lifestyles. The youths proposed innovative solutions for these causes, such as establishing a guesthouse, revitalizing unused space, creating opportunities for dialogues, developing bamboobased environmentally friendly products, and holding local activities; (2) the youths constructed a model for internal cooperation and enhancement, revitalization, and marketing Zhushan Township; (3) the youths advocated for various social values, utilized social capital, and proposed innovative solutions through diversified participation and the creation of new relationships, allowing different communities to generate a group dynamic to resolve social problems and achieve sustainability together. This study aids in the facilitation of sustainable management of township micro-enterprises by innovating products and service modes through social capital and social value. At the same time, local and common social innovation modes are connected to provide a reference for the social innovation of micro-enterprises.
\end{abstract}

Keywords: Zhushan Township; youth-led bamboo craft brand; social innovation design; sustainability

\section{Introduction}

Before the 1980s, Zhushan Township in Taiwan was once an important town where $70 \%$ of the population was engaged in the bamboo industry economy. After industrial transfer and population migration, the population decline slowed down in the recent three years, from $-0.99 \%$ to $-0.28 \%$, and the town has been faintly attractive [1]. In 1994, the Ministry of Culture initiated the community building policy, and the farmers' associations and town offices in bamboo-producing areas set up bamboo craft training courses one after another to train local bamboo art technical talents, drive the local economic production capacity, and beautify the hometown environment [2]. When the 921 earthquake occurred in Taiwan in 1999, Zhushan Township was the hardest hit area, which led to the increase in population migration and promoted regional activation and industrial reengineering through community building [3]. In 2002, the bamboo craft industry encountered a new opportunity, and the Ministry of Culture launched two five-year Cultural and Creative Industries programs in succession to boost the craft industry by design [4]. In 2003, UNESCO passed the Convention for the Protection of Intangible Cultural Heritage. Consequently, the inheritance of bamboo art was paid more attention [5]. In 2005, the National Taiwan Craft Research and Development Institute (NTCRI) promoted the Local Craft Characteristic Counseling-Community Craft Support Plan, in which craftsmen developed local craft products together with community residents, university teachers, and students to form local industries. From 2008 to 2013, the NTCRI and Taiwan Creative Design Center jointly 
launched the five-year Craft Fashion Yii Plan, which promoted the whole bamboo process design to the international stage. In 2019, Zhushan Township, as one of the 134 townships promoted by Taiwan's Regional Revitalization Policy, attracted more resources for youth entrepreneurship and the local economy.

The Forestry Bureau of Taiwan cooperated with the Industrial Technology Research Institute (ITRI) to improve the performance of bamboo materials. Through anti-corrosion and stratification technologies, the tolerance of bamboo can be improved, and its strength can even be close to steel. In this way, bamboo can be used to build roof beam structures [6]. The Forestry Research Institute mainly focuses on bamboo forest management and resource investigation, bamboo forest carbon storage research, counseling bamboo farmers to build bamboo charcoal kilns and produce bamboo charcoal, and bamboo processing and application [7]. Thanks to the use of bamboo as an ecological material, it is possible to implement eco-innovations and join the closed-loop economy [8].

In the past five years, the old, middle-aged, and young generations who worked outside, returned home to start businesses one after another. People from different countries and regions traveled to Zhushan. In addition, universities, governments, non-profit organizations, and other institutions came to Zhushan to carry out social practices, of which more community residents participated. Although the actions of the youths have been affirmed by society, there are still many obstacles for young people in starting businesses in rural areas, such as breaking old ideas, tackling key technical problems, and restricting marketing channels. So, how do they overcome difficulties, launch social innovative design actions, and promote the concept of sustainability? In light of the five youth-led bamboo craft brands of Zhushan Township, the research purposes are as follows:

(1) Analyze the content and characteristics of social innovation design and sustainability of these brands;

(2) Analyze the social innovation design and sustainable mode of these brands;

(3) Analyze the relationship between the social innovation design and sustainability of these brands.

This paper discusses the social innovation design and sustainability of Zhushan's five active youth-led bamboo craft brands. Further, it provides a reference for the sustainable development of micro-enterprises in villages and towns, participating in industrial innovation and social innovation with design, and boosting local revitalization.

\section{Literature Review}

\subsection{Bamboo Craft and Youth-Led Bamboo Craft Brand in Zhushan}

Faced with the problem of sharp shrinkage of the bamboo industry since the 1980s, Zhushan Township, an important place of bamboo craft, and Taiwan craft management units have made great efforts in the inheritance and development of bamboo craft, offering a large number of courses and cultivating bamboo artists. In addition to skill inheritance, the NTCRI's bamboo talent cultivation course focuses on product development, bamboo application, technology research and development, and brand marketing [9]. The Taiwan Forestry Research Institute used surplus bamboo materials to develop special paper products. This technology can promote recycling in the bamboo industry and provide a reference for pulp and paper mills and other industries in the production, research, and development of special papers [10].The Forestry Bureau studied the influence of bamboo forest composition, new bamboo growth, and forest land regeneration and applied modern machinery [11].Through resource inventory and cross-border integration, the Townway Cultural and Creative Corporation introduced cultural creativity to local areas, constructed a diversified and all-around development mechanism, stimulated residents to participate in local affairs, encouraged young people to return home, and established local brands [12]. Through the business model, social enterprises make use of the ecosystem to provide diversified resources, make the overall operation more effective, and save money-at the same time [13], rediscover themselves and places, and move towards the practice of reciprocal value [14]. 


\subsection{Social Innovation Design}

\subsubsection{Origin and Connotation of Social Innovation}

Eleanor Shaw pointed out that the practice of social innovation began in Britain in the 19th century when a few charitable entrepreneurs noticed that the improvement of the working environment, education, and cultural life helped enhance the well-being of employees [15]. In 2003, the OECD considered that social innovation aims at social and economic problems and improves the quality of life of the people and the general public by rediscovering and giving new services and solutions [16]. Social innovation is an innovative model with scientific and technological needs, platforms, and organizations [17]. Schumann et al. divided organizational innovation into product innovation, process innovation, and program innovation [18]. Additionally, economist Harvey Brooks stated that organizational innovation should come first [19].

In 2007, British economist Geoff Mulgan and others believed that "Social innovation" is defined as "innovative activities or services motivated by meeting social needs, whose main purpose is to affect the entire society." [20] Defined by James Phills, Professor of Stanford Social Innovation Organizational Behavior in 2008, "A novel solution to a social problem that is more effective, efficient, sustainable, or just than existing solutions and for which the value created accrues primarily to society as a whole rather than private individuals" [21]. Social innovation involves the interplay of resources, environmental factors, and interactions between actors [22].

The characteristics of social innovation [23]: (1) comprehensiveness; (2) openness; (3) pluralistic participation; (4) decentralization. The so-called decentralization is to give full play to the initiative and creativity of the bottom-most organization and distribute the decision-making power to the subordinate organizations [24]; (5) super social responsibility; (6) relevance [25]. Social innovation is the combination and recombination of social practices [26]. Putnam believes that social capital includes networks, norms, and trust in social life so that participants can act together and achieve their goals effectively [27]. Onyx and Bullen pointed out that social capital includes participation, trust, network, reciprocity, and norms [28]. Many companies with little infrastructure, regulatory authority, or money to respond to newcomers' immediate needs or make longer-term integration investments [29].

\subsubsection{Definition and Content of Social Innovation Design}

Victor Papanek deemed that designers should pay attention to the needs of society, the environment, and design for $90 \%$ of the general public in the world [30]. Tim Brown of IDEO, a design innovation company, emphasized that design thinking is optimistic, constructive, and experiential in nature, which can meet people's needs for products and services [31]. Social innovation is to apply knowledge and meet the needs of the public. Meanwhile, the operation method can obtain social resources, social support, and promotion [32]. As the concrete implementation of social innovation is through social design, it can be seen that social innovation design uses social resources and knowledge to meet the needs of society and put forward innovative schemes.

Dr. Ezio Manzini stated, "Social innovative design is all the activities that professional design can implement to activate, maintain and guide society towards sustainable development". Only on the basis of establishing contacts can small local organizations have a large-scale impact. Under the positive influence of the network age, there is another possibility to avoid structural bureaucracy; that is, through horizontal and vertical connections [33]. In the connection strategy stage, it is necessary to achieve scale improvement through connection, where design schools play an important role. He argued that the emerging trend in design is gradual networking [34], which shows that design schools can become cultural institutions for social innovation. The potential of design schools may be a collaborative social resource, becoming an active key, and having a creative role in sustainable development [35]. The development and popularization of the internet provides a new channel for rural service innovation, showing the following characteristics [36]: 
(1) diversified service roles [37]; (2) localization of service content and resources [38]; (3) network communication of service vision. At present, villagers lack willingness and have a weak perception of the value of rural culture. Economic development has become the biggest factor in guiding villagers to participate in cultural revitalization [39], which is necessary to spread the vision [40]. A spike in community solidarity and a resurgent appetite for cross-stakeholder solutions based on multidisciplinary know-how could make this a historic opportunity for social innovation to strengthen community resilience [41].

\subsection{Sustainability}

Sustainable development is defined as a development model that can meet our present needs without damaging future generations' ability to meet their needs [42]. In September 2015, the United Nations issued Transforming Our World: The 2030 Agenda for Sustainable Development through the agreement of SDGs (Sustainable Development Goals). This policy plans 17 sustainable development goals, taking into account three major aspects: economic growth, social progress, and environmental protection [43]. In 2004, Dr. HuaShan Guan sorted out the essentials and practices of a sustainable community mentioned by many scholars (Kline, Hancock, Roseland, Barton) and summarized them as follows: (1) economic sustainability: having the ability to maintain its own economic development, green business, create new products, update the operation mechanism of the community, and achieve its own economic balance operation; (2) social sustainability: paying attention to the organization and operation of the community, establishing the consensus of residents for the community, establishing the mutual benefit mechanism of neighboring areas, and improving the local autonomy and social responsibility of the community; (3) environmental sustainability: the management and application of community environmental practices, including waste reduction, recycling, local resource management, etc. [44]. The DfSS framework specifically encourages designers to create solutions that are not just user-focused, but are systems-focused. Rather than focusing on how products can solve people's needs, we draw attention to how the entire product lifecycle (including design, manufacture, use, and maintenance) can maximize social impact [45].

\subsection{Social Innovative Design and Sustainability}

The shift to a low-carbon community needs the transformation of government functions, improvement of a community system, and citizens' participation [46,47]. Social innovation realizes the harmonious relationship among people, the environment, and society through pluralistic participation [48]. People and designers design together and participate in constructing a low-carbon community, which can not only meet residents needs to the maximum, but also promote community development [49]. Designers should re-understand their value, understand the inner spirit and meaning of culture, fully communicate with the locals, and jointly develop necessities suitable for local life, circulating commodities, and even international products with a high added value [50]. Chang Wenshan, a design scholar in Taiwan, believed that SDGs correspond to USR in Taiwan, and through the companionship and squatting of university teachers and students in the community, it will produce a closer sense of connection and carry out social practice programs for local problems. These will form a testing ground for sustainable management that practices commercial, social, cultural, and ecological values [51]. Chris Ryan, an expert in the field of social innovation, stated that "the distributed system model has attracted increasing attention, and it is regarded as a way to build a sustainable economy" [52]. He further remarked that "distributed models place and arrange infrastructure and critical service systems near resource and demand points. Individual systems can operate independently and adjust themselves, while also connecting with larger local, regional, or international networks" [53]. Distributed systems learn from problems and are more resilient than mainstream vertical systems [54]. Moreover, the necessary condition for a sustainable society is recoverability [55]. 


\section{Methods}

The four elements of qualitative research are building relationships with the subjects, sampling, data collection, and data analysis, all of which determine the value and validity of the conclusions of the research [56]. The subjects of this study were five bamboo craft brands created by young entrepreneurs in Zhushan Township, namely, Townway Cultural and Creative Corporation (hereinafter Townway), Yuantai Bamboo (hereinafter Yuantai), KYOU Bamboo Design (hereinafter KYOU), La-boos, and Bamboo-Lai Culture \& Creation (hereinafter Bamboo-Lai). The leaders of these brands met at the Spotlight Meetup activity held by Townway, which cultivated their new start-up brands. They have cooperated to revitalize Zhushan through social connections based on design. The 5 years of their cooperative relationship was also a period in which Zhushan experienced an eruption of collective power used to generate social influence.

\subsection{Research Procedure and Methodology}

The 5-year research process spanning from September 2016 to June 2021 comprised the following three steps: (1) preliminary preparation and field observation: documents were analyzed to collect textual information regarding the topic, and several field surveys were conducted to screen samples and identify the subjects; (2) observation and data collection: observation and interviews were conducted with stakeholders of the five youth-led bamboo craft brands, such as the leaders of the brands, bamboo craftsmen, college teachers and students, and local residents; (3) data analysis and collection: grounded theory was used to code, analyze, and organize the data, followed by an evaluation using social innovation design and sustainability theories derived from the literature; the goal was to study the social innovation design of youths in the bamboo craft industry and its sustainability.

\subsection{Research Data Collection: Observation Method and Interview Method}

From September 2016 to June 2017, the author, a student, used participant observation to study the subjects and their environment, drawing from the long-standing collaboration between the author's school and Zhushan to naturally establish amicable relationships with the subjects. The author gradually established a relationship of trust and understood the context of the research through participation in several public events held by the brands and exchange and dialogue with related personnel. In-depth investigations began after 1 year of preliminary preparation and observation. From March to December 2017 and from September 2018 to June 2019, the author entered the field multiple times and actively participated in various activities related to the brands. The events were documented through images, audio recordings, and field notes that were used as first-hand observational data and, subsequently, organized. Table 1 lists the main events held by the young entrepreneurs from September 2016 to June 2019.

This study also conducted interviews with 15 key figures in the youth-led bamboo craft start-ups, including those with the stakeholders of the five brands. Each figure was interviewed approximately 1-3 times, and each interview lasted approximately 1 to $2 \mathrm{~h}$. The interviews were open-ended, semistructured, and were conducted between May 2017 and May 2019. The interviews revolved around the brands' entrepreneurial process, ideas, product innovations, participation in events, cooperative projects, and marketing channels. The interviews were conducted with key figures knowledgeable about social innovation behavior and sustainability to achieve saturation, as shown in Table 2. 
Table 1. Summary of main events held by the youth-led bamboo craft brands in Zhushan from 2016 to 2019.

\begin{tabular}{|c|c|c|}
\hline Time & Event and Venue & Contents \\
\hline 14 November 2016 & $\begin{array}{l}\text { Store survey: Beyoung Garden and Yuantai. } \\
\text { Venue: Zhushan Station, Taisi Bus Station. }\end{array}$ & $\begin{array}{l}\text { Observation of everyday operations of the stores; } \\
\text { understanding of the products and consumers. }\end{array}$ \\
\hline 31 March 2017 & $\begin{array}{c}\text { Workshop guiding young entrepreneurs in their } \\
\text { design of services led by Professor from National } \\
\text { Yunlin University of Science and Technology } \\
\text { (YunTech). } \\
\text { Venue: Bamboo Nest Class. }\end{array}$ & $\begin{array}{l}\text { Implementation of a local revitalization guidance } \\
\text { program; the role of YunTech post incubation. }\end{array}$ \\
\hline 7 May 2017 & $\begin{array}{c}\text { Forum on regional revitalization; reversing } \\
\text { design; shaping the features of a town of tea } \\
\text { and bamboo. } \\
\text { Venue: Beyoung Garden. }\end{array}$ & $\begin{array}{l}\text { Collaborative discussion about regional } \\
\text { revitalization between companies, organizations, } \\
\text { YunTech, governments, the Ministry of } \\
\text { Education, and residents of Zhushan and Lugu. }\end{array}$ \\
\hline 19 May 2017 & $\begin{array}{l}\text { Spotlight Meetup activity: workshop on channel } \\
\text { and industry guidance by Bright Ideas Co., Ltd. } \\
\text { Venue: Bamboo Nest Class. }\end{array}$ & $\begin{array}{l}\text { Improving the products of the young } \\
\text { entrepreneurs; curatorial preparation; counseling } \\
\text { on brand marketing strategies. }\end{array}$ \\
\hline $\begin{array}{l}15 \text { October } 2017 \\
23 \text { October } 2017\end{array}$ & $\begin{array}{l}\text { Survey of young entrepreneurs' workplace. } \\
\text { Venue: stores and manufacturing plants of } \\
\text { five brands. }\end{array}$ & $\begin{array}{l}\text { Understanding the young entrepreneurs' work } \\
\text { environment, jobs, production processes, and } \\
\text { marketing channels. }\end{array}$ \\
\hline
\end{tabular}

Reversing Design: Regional Revitalization (a

1 December $2017 \quad$ special joint exhibition at the end of the program). Taipei.

Store survey: five young entrepreneurs and other

10 May 2018

23 May 2018

6 October 2018

26 October 2018

10-11 November 2018

Zhushan Culture Regional Revitalization Festival.

Venue: Zhushan Station (Taisi Bus Station).
Town Fair in Zhushan.

Venue: Zhushan Station, Taisi Bus Station.

Spotlight Meetup activity: preparation for Zhushan Culture Regional

Revitalization Festival.

Venue: Bamboo Nest Class.
Evolution of young entrepreneurs' management and ideas and planning for future development with the Spotlight Settlement ecological mechanism.

Trial run of Regional Revitalization Festival 1 month before; DIY bamboo weaving; exhibition of the brands.

Presentation by $\mathrm{Pu}$ Yuan and Bamboo-Lai; the representative of Yuantai explained the preparation for Revitalization Festival in Zhushan with the help of local residents.

Events such as handicraft workshops and local cuisine presentations; participation of young entrepreneurs, arts and cultural groups, government officials, residents of Zhushan, and tourists from other regions.

Teachers and students from the Department of Industrial Design of YunTech shared their design projects using recycled bamboo; presentation by Townway about Digital Townee program.

Young entrepreneurs' product and brand management and event organization; local residents and local organizations.

Strategy for cultivating young entrepreneurs in Zhushan between 2017 and 2019.

Observing tourists, local residents, and the operations of Bamboo Life Cultural Association and Building a Mountain City. 
Table 2. Summary of interviews with 15 key figures from 2017 to 2019.

\begin{tabular}{|c|c|c|}
\hline Brand & Identity Code & Background \\
\hline \multirow{6}{*}{ 1. Townway } & Townway representative (1A) & $\begin{array}{l}\text { From Shuili, Nantou; specializes in medical } \\
\text { management; entrepreneur in Zhushan for } 16 \text { years; } \\
\qquad 2 \text { years old now. }\end{array}$ \\
\hline & Townway staff (1B) & From Penghu; worked in Townway for 3 years. \\
\hline & Beyoung Garden representative (1C) & Cousin of Ho; worked in Zhushan for 5 years. \\
\hline & $\begin{array}{l}\text { Tour Guide at Townway; } \\
\text { bamboo artisan (1D) }\end{array}$ & $\begin{array}{l}\text { Bamboo artisan in Zhushan; experience } \\
\text { collaborating with designers for many years; worked } \\
\text { in Zhushan for almost } 40 \text { years. }\end{array}$ \\
\hline & $\begin{array}{l}\text { Professor, in charge of industry-academia } \\
\text { collaboration with YunTech (1E) }\end{array}$ & $\begin{array}{c}\text { Digital media teacher at YunTech; main counselor for } \\
\text { young entrepreneurs; 10-year collaboration. }\end{array}$ \\
\hline & $\begin{array}{l}\text { Student of specialty-based exchange } \\
\text { accommodation (SBEA) stationed at } \\
\text { Townway (1F) }\end{array}$ & $\begin{array}{c}\text { Third-year master's student taught by Professor } \\
\text { who stayed in the town for } 6 \text { months through } \\
\text { SBEA program. }\end{array}$ \\
\hline
\end{tabular}

2. Yuantai

Yuantai representative (2A)

Third-generation Zhushan resident; entrepreneur in Zhushan for 9 years; family owned a factory; 38 years old now.

Yuantai staff (2B)

From Nantou; young girl who had moved to the town 3 months prior.

Second-generation Zhushan resident; specializes in design; returned to Zhushan 10 years prior; created KYOU representative (3A) his brand 4 years prior; family owned a factory; 40 years old now.

3. KYOU Representative of Pure Soap who cofounded Goods store with 3A and 4A (3B)

Representative of Forest Noodles collaborating with $3 \mathrm{~A}(3 \mathrm{C})$

4. La-boos

Representative of La-boos (4A)

Collaborator of 4A for AxMon Art (4B)

Representative of Bamboo-Lai (5A)

5. Bamboo-Lai

Father of Bamboo-Lai representative (5B)
Son-in-law of Zhushan resident; specializes in design; entrepreneur in Zhushan for 5 years; full-time designer at a hospital.

Second-generation noodle chef in Zhushan; specializes in design; entrepreneur in Zhushan for 6 years; built a tourist factory with a loan.

Second-generation Zhushan resident; specializes in business management; entrepreneur in Zhushan for 6 years; family owned a factory; 37 years old now.

Daughter-in-law of Zhushan resident; specializes in design; entrepreneur in Zhushan for 5 years.

Second-generation Zhushan resident; specializes in catering management; entrepreneur in Zhushan for 5 years; family owned a factory; 42 years old now.

First-generation Zhushan resident; bamboo craft teacher at National Chushan Senior High School; tutored bamboo crafts overseas for many years; worked in Zhushan for over 50 years.

\subsection{Analysis and Organization of Research Data: Grounded Theory and Document Analysis}

Coding is the basis of data analysis in grounded theory. The organization and refinement of data during the coding process allows for key categories to be identified. Some concepts related to a category serve as subcategories. By using the $\mathrm{KJ}$ method, the core category can be identified from the main categories [57]. The founder of KJ method is Tokyo humanist Jiro Kawakita, KJ is his English abbreviation. KJ method is to collect different data and classify them according to the relationship between them [58]. In this study, the field notes and interviews were formatted into verbatim transcripts, numbered, and decoded to organize the textual materials. The subcategories were then identified, 
and the KJ method was used to determine the main categories and construct chapters. New problems and issues that emerged during the collection and analysis of the data were revised or supplemented and analyzed in depth through a literature review and the field notes.

The process from data decoding to category construction for Townway was as follows: (1) numbering the field notes: the notes were numbered by time of observation and event using abbreviated keywords. For example, 20170507 represents the date of a local forum on shaping the features of a town of tea and bamboo ("tea and bamboo" was abbreviated as "TB"). The subtopics of major events were noted in each paragraph. The host's opening remarks and the guests' speeches were subtopics of the forum and were numbered in ascending order $(01,02,03$, and so on). Each paragraph was then open coded in ascending numerical order $(-1,-2,-3$, and so on); (2) numbering the verbatim transcripts: the transcriptions of the interviews were organized using a system of four alphanumeric codes. The first code represented the brands, which were numbered 1, 2, 3, and so on. The second code represented the interviewees, who were designated as A, B, C, and so on. The third code represented the order in which events were mentioned during the interviews: $01,02,03$, and so on. The fourth code was the open code for an event, designated as $-1,-2,-3$, and so on; (3) grounded theory was used to integrate the open codes into a textual description of specific behaviors followed by classification of the subcategories. The subcategories were grouped into the main categories using the KJ method and used as the chapters for the analysis of the results; (4) finally, the conclusion was developed through a theoretical evaluation and dialogue with the interviewees.

This study reviewed articles, academic journals, dissertations, newspapers, magazines, and online data on issues related to Zhushan Bamboo Craft, Sky Yard guesthouse, Townway, social innovation design, and sustainability. A total of 86 books, 320 journal articles, 87 dissertations, and 163 media reports were reviewed. Section 2 presents the literature review, from which the following four dimensions of social innovation design evaluation were extracted: (1) analyzing social needs and using social capital [20,27,28,30-32]; (2) encouraging diversified participation and proposing solutions [17,18,21,23,24,37]; (3) generating group motivation and forming new connections [25,26,33,34,38-40]; (4) solving social problems and achieving sustainability $[48,49,51,53-55]$. The following three dimensions of sustainability were obtained identified from the literature review and the 17 sustainable development goals proposed by the United Nations: (1) economic sustainability [42-44,50]; (2) social sustainability [42-45]; (3) environmental sustainability [42-45]. A total of seven theoretical aspects (Figure 1) were used to evaluate the five brands investigated in this study, and their performance in terms of social innovation design and sustainability was comprehensively analyzed.

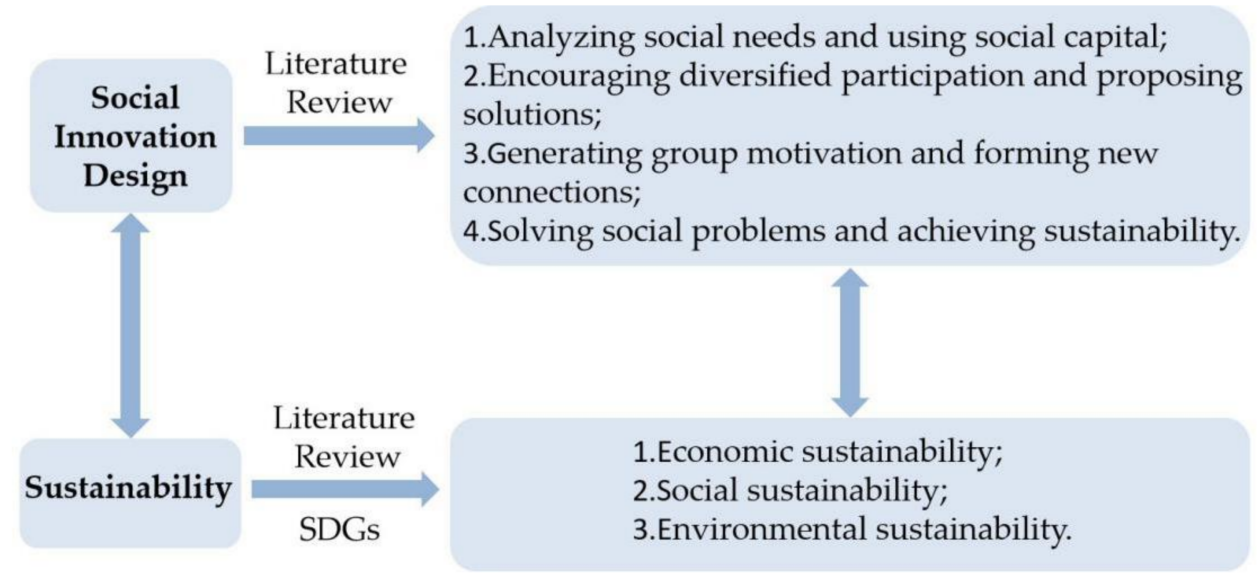

Figure 1. Social Innovation Design and Sustainability Theory Evaluation Orientation. 


\section{Analysis and Results}

The young entrepreneurs of the bamboo craft brands in Zhushan launched innovative movements centered around bamboo. Among the brands, Townway is an agent of resourceintegrated social innovation, and Yuantai is a model for industrial innovation. The others, namely, KYOU, La-boos, and Bamboo-Lai, are microentrepreneurial brands. Before the young entrepreneurs started their businesses in Zhushan, they had gained professional experience in management, design, and manufacturing. Four of the young entrepreneurs are locals of Zhushan, and their families once owned bamboo factories.

\subsection{Townway}

From the founding of the Sky Yard guesthouse in 2005 to the creation of Townway, this company has been in Zhushan for 16 years. The founder is a key figure in the young entrepreneur community, he preserves local culture and history and solves social problems. He has continued to introduce external resources to Zhushan while exporting its practice of sustainable development [59].The development process can be divided into three periods: (1) renovating a three-section residential compound (Sanhe Yuan) into the Sky Yard guesthouse: linking community resources on and off the mountains and attracting tourists (2005-present); (2) the founding of Townway and the process of becoming an intermediary in dialogue between locals and outsiders to cocreate value for the common good (2010present); (3) shaping the Spotlight Gathering Settlement at Taisi Bus Station, incubating the Town's ecological mechanism to maturity, and the revitalization and marketing of Zhushan by young entrepreneurs in preparation for the Asia Revitalization Platform (2015-present).

4.1.1. Renovating a Three-Section Residential Compound (Sanhe Yuan) into the Sky Yard Guesthouse

1. Changing the negative perceptions of rural areas: using the natural and cultural features of the mountains as selling points for the guesthouse

In 2004, the founder began to sense a decline in culture and developed an idea of preserving culture through a guesthouse. After many challenges, in 2005, he completed the restoration of a century-old Sanhe Yuan and maintained its original appearance [60].

2. Changing the negative perceptions of the old mansion: conveying the cultural and historical value of a century-old house to visitors the text continues here

After the guesthouse space was built, they drafted informative texts, marketing copy, and self-recommendation letters to various departments of the government. They, then, created a website and promoted the guesthouse through a bulletin board system. Whenever tourists stayed in the $B \& B$, the founder would project a film in the courtyard in the evening. The film was a documentary that explained the process of restoring the guesthouse and his concept of cultural preservation and entrepreneurial management. A major turning point occurred in December 2005, when the Nantou County Government invited internationally renowned musician to stay in the guesthouse and compose the eponymous album "Sky Yard", for which he received a Golden Melody Award [61]. This led to consistent coverage by TV channels and magazines, and the number of visitors rapidly increased. The founder was also invited to give speeches. During this time, he documented daily events on Facebook to convey his thoughts on cultural preservation and local development.

3. Reversing the tourism model for famous scenic spots: promoting Da-an community resources through tourism

From 2006 to 2009, the company developed the Da-an community by turning an unused tea factory into a restaurant, restoring the Da-an Historic Trail, and "thinking about business from the perspective of the common good" (1A02-3). They created tour itineraries with activities entitled "Reading on the Mountain, Dining in the Sky" and "Leisurely Paced Experience Tour with Lunchboxes," which not only enriched the travel experience for tourists, but also provided resources and improved the environment for the community, thereby working together with residents to create a local value. 
4. Reversing the village tourism paradigm: turning tourists into social observers that contribute to cultural value

The founder stated that with such policies in place, "the place loses its characteristics; the economy is irrelevant to the locals, and local culture and education are ignored" (1A04-1). Thus, they connected the guesthouse, tea gardens, and Tianti Scenic Area on Da-an Mountain to the traditional shops at the base of the mountain. They created a program in which travelers gained authentic experience visiting a puffed rice store, an iron maker, and a quilt shop in Zhushan. At the beginning of the "Leisurely Paced Experience Tour with Lunchboxes" activity, the participants watched a documentary about the history of the Da-an Historic Trail in a restaurant, and each participant received a lunchbox designed by college students. The lunchboxes were wrapped in a bamboo mat and camellia cloth hand sewn at an old quilt shop in the town. The meals in the lunchboxes were prepared with ingredients from the local market [61].

5. Reattaching tourist guesthouse to local products: supplies from local industry and the first-hand experience of local charm

The household products in the guesthouse, such as the bed sheets, utensils, lighting, and snacks, were locally produced, and every aspect of the accommodation told a story about the community. Travelers who wanted to purchase an item in the guesthouse after using it could scan a $\mathrm{QR}$ code for more information. Thus, the guesthouse became a vehicle for local culture and generated a diverse range of revenue streams while benefitting the local economy (1A01-2).

6. Reversing the business model of traditional stores at the base of the mountain: the manufacturing process as a service model for tourism

The old stores in Zhushan retain traces of the traditional Taiwanese lifestyle. The linking of the local companies, stores, and the community encouraged the stores to change their service model to allow tourists to visit and learn and increased sales by $20-30 \%$. For example, the owner of a puffed rice store strengthened his dedication and confidence in the industry by presenting his products and manufacturing process to tourists: "tourism brings a steady flow of visitors and income to my store and renews my confidence in the production process" [62].

\subsubsection{The Founding of Townway}

1. Turning untapped resources into opportunities: cooperating with local designers through specialty-based exchange accommodation

By the time the operations of the guesthouse had stabilized, Zhushan was still experiencing economic problems and youth drain. To solve these problems, they founded Townway in 2010 to connect local businesses, arts and culture, and ecology while attracting external resources. Townway rented an inexpensive vacant house and turned it into a youth hostel for the specialty-based exchange accommodation (SBEA) program. The town developed by exchanging local characteristics for external creative talent and drawing resources from society: "sometimes, in certain months, there are more than 30 people here at once. They're asked to write a travel log and discover a new story every day" (1B10-3).

In less than 2 years, more than 600 students went to Zhushan for SBEA and assisted local businesses in developing products, shooting short films, and improving the environment, and demonstrating the beauty of the tea gardens amid the bamboo forests and the diligence of Zhushan locals.

2. The public sector's focus on the common good: the cocreation of an online platform and products by locals and society

Townway has received subsidies from several public sector programs. For the Small Business Innovation Research program of the Ministry of Economic Affairs in 2011, Townway created an online platform for sharing information on stores, travel itineraries, and narrators. The platform also featured collaborative itinerary and cultural and creative 
product design. On the platform, locals co-worked with society to create demand, which drew participants and strengthened the competences of the companies and the town. After the online platform was established, the number of tourists increased; tour guides proposed itineraries, designers received projects, and companies could request product customization. The township office also recruited volunteers through the platform [63].

3. Drawing labor, funds, and ideas from universities and cooperating with local stores and organizations to shape local products and services

Since 2011, The founder has given hundreds of lectures annually at universities and participated in an industry-academia cooperation that allowed students to help transform the town with their expertise. For example, students cooperated with the Lai Far Blacksmith Shop, which originally manufactured agricultural tools, to make couple rings and assisted the Chiming Mifu store in developing new brown sugar and spicy flavors for the shop's products [64].

In 2012, Townway and mothers in the community established the Bamboo Life Cultural Association to promote the bamboo craftsmanship of Zhushan. In 2013, woven bamboo QR codes for use as local merchant signboards were developed with the support of the Smart Life Integration Talent Program of Nankai University of Technology (NANKUT). The participants from NANKUT proposed the idea of combining bamboo weaving with digital technology. Participants from Southern Taiwan University of Science and Technology used plastic panels to protect materials; final improvements were conducted by students from the National Cheng Kung University. Members of the association were responsible for producing all the materials and the woven bamboo [60].

4. The creation of the Bamboo Nest Class, a space for co-learning, and the Local Forum, an opportunity to exchange knowledge of local operations, revitalize the community, and reaffirm local identity

Zhushan required dialogue with schools, youths, residents, and enterprises. In 2012, through an industry-academia collaboration, Townway and YunTech completed the construction of the Bamboo Nest Class, a space for co-learning. In 2012, the venue for the Miaokou TED Talk event was changed to the Bamboo Nest Class, and the lectures became the Local Forum, a free event with no speaking fee. The event was regularly held from 7:00 p.m. to 10:00 p.m. on the last Friday of each month. At the event, entrepreneurs in Zhushan presented their plans, and issues, products, services, and local connections in Zhushan were discussed [61]. The event was also open to participants from outside Zhushan. Participants from various fields came together to communicate and share their practical experience and knowledge. The event encouraged youths to care about their hometown and created a sense of identity among the public (1A08-2).

5. Bringing local visibility and economy to Zhushan: strengthening the connection among homecoming youths and creating a structure of mutual support

From 2011 to 2014, SBEA, cultural creativity, and groups of local young entrepreneurs began to flourish in Zhushan. For example, one girl who had returned to her hometown to open a beef noodle shop remarked, "because of our involvement with Townway, the shop has gained exposure, and its performance has improved". Another girl who operated a dessert shop stated, "Townway allows young entrepreneurs such as us, who have returned to their hometown, to support one another and connect, and it shows people our devotion and sincerity" [62].

\subsubsection{Shaping the Spotlight Gathering Settlement at Taisi Bus Station}

1. Revitalization of the second floor of the bus station into Beyoung Garden and the use of local characteristics to create an aesthetic for the bamboo dining space

The Taisi Bus Station in Zhushan had long been unsanitary, with betel nuts and cigarette butts strewn everywhere by the roaming taxi drivers. In 2015, Townway rented the second floor of the Taisi Bus Station and transformed the long-unused staff dormitory into Beyoung Garden (Figure 2), which was completed in early 2016. The space was 
designed using the random method of bamboo weaving. The project staff remarked that $\mathrm{Su}$ used to make woven bamboo products: "this is the first time she integrated bamboo weaving into a space. Participating in the production process opened her up to a new direction: creating a bamboo space" (1B17-5). The manager of Beyoung Garden explained that visitors could sample multicourse meals created with various bamboo products. The famous sweet potatoes, bananas, and pineapples of Zhushan were also used to make the snacks and drinks: "old stores that have been around for more than 40 years, such as the Chiming Mifu store and the puffed rice shop, created special milk tea and Da-an Mountain coffee" (1C03-2). In addition to Beyoung Garden's function as a restaurant, the space held occasional exhibitions (Figure 3) and public events for local entrepreneurs.

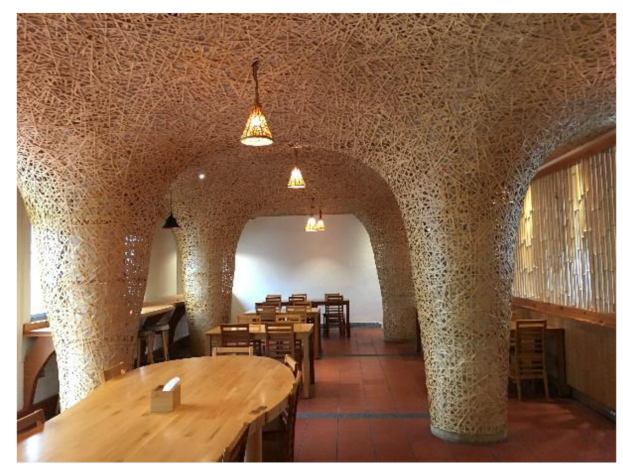

Figure 2. Beyoung Garden.

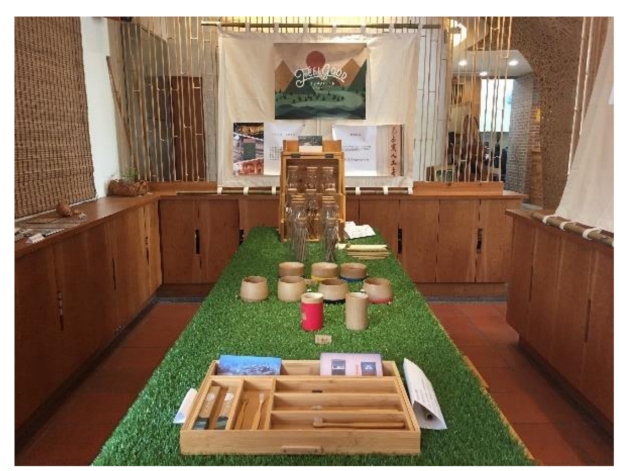

Figure 3. Exhibition space.

2. The transformation of the Local Forum into the Spotlight Meetup activity, the steady growth of local and social capital, and the internal convergence of Zhushan's entrepreneurial power

Many start-up brands began to emerge in Zhushan in 2015. In response, the Local Forum was reorganized into the Spotlight Meetup activity, but the venue remained the Bamboo Nest Class. Young entrepreneurs used the platform to discuss their needs and experiences, and Townway proposed ideas for the following month. Participants included college teachers, students, and residents of Zhushan as well as residents from other counties and cities who were interested in Zhushan. Together, the group formed a community based on continuous learning rooted in entrepreneurship in Zhushan.

3. Townway designs tours and connects young entrepreneurs with local companies through a mutually beneficial relationship

The tours developed by Townway consisted of five parts which visitors could select to suit their needs. In the first part, the tourists visited Beyoung Garden and the youth exchange accommodation, painted walls and the headquarters of local entrepreneurs, and listened to Townway staff share their ideas at the Bamboo Nest Class. In the second part, the tourists listened to a young founder of a company in Zhushan discuss his entrepreneurial 
process and experience with bamboo craftsmanship. In the third part, the tourists sampled foods created with local ingredients at Beyoung Garden. In the fourth part, the tourists observed the manufacturing processes of the products sold in old shops and visited factories. In the fifth part, the tourists enjoyed the scenery of the Da-an Mountain and the century-old Sanhe Yuan at the Sky Yard guesthouse (1B18-6).

4. Expanding young entrepreneurs' knowledge, vision, and marketing channels through the support of the University Social Responsibility program and regional public sector revitalization projects and accelerating the revitalization of Zhushan.

From 2017 to 2019, youth-led brands in Zhushan were upgraded through the Design Flip Local Creation program of Nantou County and the National Development Council hosted by YunTech, which resulted in the creation of Tea and Bamboo: the Spotlight Settlement ecological mechanism. They have held several workshops and courses, organized forums and exhibitions, gathered forces from various social sectors, cultivated youth-led brands in Zhushan, and promoted local industry and culture. The project was supported through its long-standing partnership with YunTech as well as through projects at Tunghai University, National Chung Cheng University, and NANKUT. The University Social Responsibility program of the Ministry of Education prompted colleges and the community to collaborate and implement social innovations.

The first era of regional revitalization in Taiwan began in 2019. The Regional Revitalization Festival, supported by the Ministry of Economic Affairs and the Corporate Synergy Development Center, was held at the Taisi Bus Station in Zhushan (Figure 4). Projects related to the town were combined with local values and technology through events with three different themes, namely the art of food, the skill of craft, and the joy of living, to integrate multiple fields.

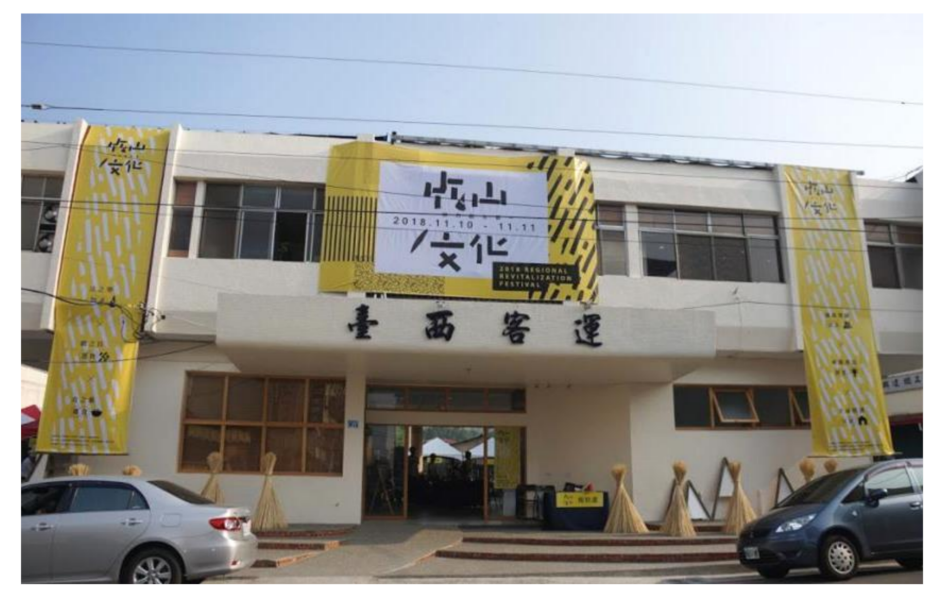

Figure 4. The Regional Revitalization Festival at Taisi Bus Station.

5. Revitalization of the first floor of the Taisi Bus Station as Taisi Ice Room: a public art space designed to attract locals and tourists

In August 2018, the first floor of the Taisi Bus Station was redesigned as a public art space (Figure 5). Local independent farmers, new residents, and senior citizens held fairs in the space, and local artists were invited to perform and exhibit their work, which attracted the locals as well as tourists. At the end of 2018, Townway established the Taisi Ice Room, an ice cream shop using local ingredients and bamboo utensils. Fruit farmers and local merchants in Zhushan collaborated to make the ice cream, and the flavors were inspired by southern France; Vietnamese coffee is used as the base of the ice cream, and it is paired with a small slice of French bread: "Because there is a Vietnamese grocery store in front of the bus station, there are many new residents around" (1A20-4). 


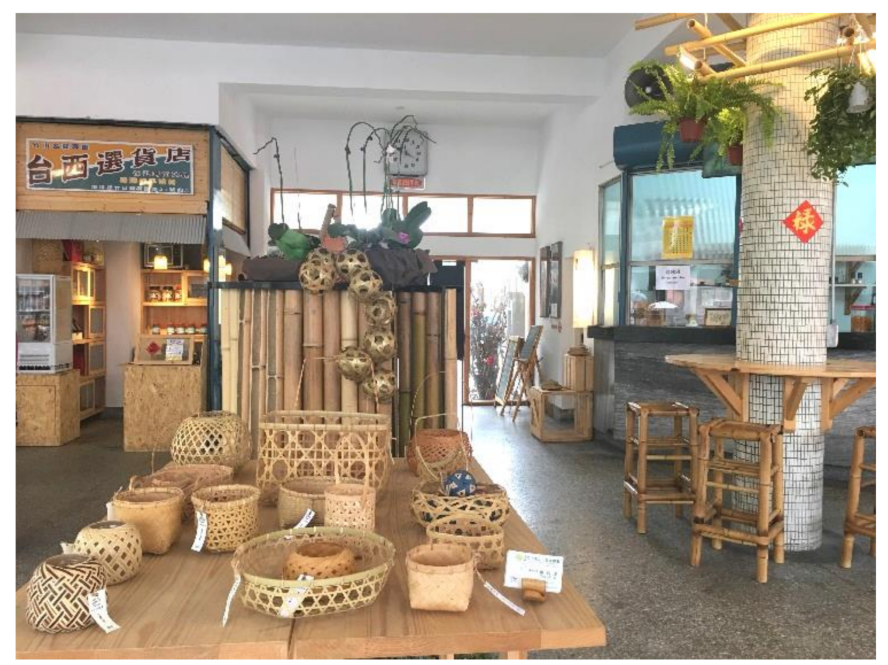

Figure 5. The first floor of the Taisi Bus Station.

6. The Spotlight Gathering Settlement at Taisi Bus Station and the creation of an ecological mechanism: marketing Zhushan through local output

The Spotlight Settlement ecological mechanism was a means of encouraging homecoming youths to start their own businesses and bring innovation to the industries in Zhushan through their ideas and creativity. The partnerships were transformed into an incubation mechanism and a system for local development. Townway's duties include hosting local programs, exhibitions, experience-based tours, the Spotlight Meetup activity, and SBEA. First, a problem is identified through the Meetup; however, a problem can become an opportunity. Next, entrepreneurs discuss their needs and pose questions, and Townway matches the entrepreneurs with resources and talent listed on the digital platform and requests external resources. Then, the brands are upgraded through SBEA to become a new force after being marketed. Lastly, after the brands mature, their products are upgraded through a combination of the experience tour and SBEA, and the brands develop featured products. Townway matched young entrepreneurs by sharing spaces, markets, resources, and preorders. As for preordering products, Townway shared stories about the young entrepreneurs during the tours, and the visitors preordered gifts and made other purchases from the young entrepreneurs. Every year, six or seven youth-led brands were incubated: "Regarding the resources, priority was given to these brands, and these brands should also correspond with the overall arrangement by Townway" (1B02-4).

In 2017, Townway introduced the youth-led brands from Zhushan to the Huashan 1914 Creative Park and cooperated with Bright Ideas Co., Ltd. Because these brands were start-ups, their product output was slightly low: "In this way, the overall output of the young entrepreneurs in Zhushan was condensed into a single force"; this force represented Zhushan's bamboo culture. (2A22-5). Introducing the products from the rural community to urban cultural and creative spaces increased the visibility of the products and formed a channel for urbanites to access local culture. In 2020, Townway added two agencies, namely, Town Empowerment and Town Intelligence, to develop overseas cooperative projects with the intent of applying the experience of revitalizing Zhushan to other countries to solve issues in their development.

\subsubsection{Evaluation Summary}

The 17 characteristics of Townway explained in the three previous sections correspond to the seven theoretical dimensions of social innovation design and sustainability identified in the literature review. Its efforts are reflected in the following four aspects:

(1) The linking of local resources and the exchange of social capital. The guesthouse has revolutionized townships, possessing value in cultural heritage and revitalizing the local economy. In addition, local resources were directed toward utilizing unused 
space and preserving the history of Zhushan to serve the public. SBEA was also used to enlist talent to support the local design efforts;

(2) The construction of public spaces such as the Bamboo Nest Class and the revitalization of the Taisi Bus Station provided a platform for local and social communication and resolved the lack of resources in the township;

(3) The close-knit collaboration between universities and the public sector provides a means for obtaining professional talent, knowledge, and funds. The collaboration also serves as an opportunity to implement social practice, which reinforces residents' confidence in local culture;

(4) The advocacy and implementation of social values. Social values are disseminated through the internet and other media to continuously implement innovative solutions, cultivate local youth-led brands, and attract like-minded individuals to engage in the cocreation process.

Because of the inherent limitations and difficulties associated with township-based entrepreneurship, certain areas were overlooked. This is reflected in the following:

(1) The limited number of business owners who benefit from matching. Because Townway is a free incubation cooperation brand that mainly focuses on providing opportunities for entities to obtain exposure and resources, some individuals or enterprises who were not included in the matching believe that they did not benefit;

(2) Less monitoring of ecological governance and sustainable development. The environmental sustainability component mainly involves the construction of bamboo crafts and the maintenance of the public space near Taisi Bus Station. Issues related to ecological governance and monitoring are seldom considered;

(3) The inefficient endogenous support system. Because the social capital mainly comes from universities and the public sector, only a small amount of business owners, youths, enterprises, and organizations in Zhushan work with Townway; the breadth of the local network is still relatively small. However, this is a common problem observed in the cultural industry and regional revitalization in Taiwan;

(4) Relatively low economic and environmental sustainability. Because the ratios of social values, social capital, and social activities are high, social sustainability is also high. By contrast, economic and environmental stability are relatively low. A more systematic business and circular economy should be established.

\subsection{Yuantai}

Yuantai is a bamboo factory with a history of 40 years with nine staff. It used to be mainly engaged in bamboo ear steak and bamboo stick needles. Due to maintenance difficulties, the third generation of bamboo artisan returned home to start a business at his mother's call in 2012. He worked in the army to repair aircraft engines for six years, where he received six months of design and drawing training. As he designed and sold T-shirts for four years (TB05-2), he was familiar with machinery, had a keen market observation, and had certain design abilities. With innovative actions, such as a road running event, bamboo products research and development, network marketing, and activity design, he closely linked brand value, life attitude, and market demand with the locals and society, and at the same time conveyed the sustainability of bamboo.

\subsubsection{Continue Road Running Events to Drive the Formation of Sports Towns}

1. Miaokou night running: the road running lasted for three years to form a sports atmosphere, addressing the lack of vitality in Zhushan

Facing the lack of social vitality in Zhushan for a long time, he thought he could hold road running events to let others know about different towns and villages. From the perspective of the local people, he thought that holding the activities at the temple entrance where people in villages and towns used to gather can best assemble crowds [60]. Those who love running in peacetime began to run on the road in groups, set up the club, Friends of Bamboo Slow Running, through Facebook social media, and called local residents to 
gather at the temple entrance every week for fun run activities. As a result, Zhushan transformed into a sports town because of its three-year continuous road running activities and its booming road running atmosphere.

2. Experience the local favor in road running: doing farm work on the road and combining large-scale activities with local food stores

He sometimes passed through the vegetable garden during his running. "When he sees the elders he knows, he helps to perform farm work and obtains two bags of vegetables for rewards. This place, unlike cities, is full of human connections" (2A01-3). Once, when runners passed through the farmland, a woman who tidied up the garden gave them some sweet potato leaves. After everyone took photos of this interesting life in running and posted them on Facebook, many people commented [60]. In the first large-scale road run, when the villagers heard that Zhushan was going to hold a big event, they were very much looking forward to it. They were initially asked for 30 rice crackers but gave 50, and the sweet potato shop also sponsored many honey sweet potatoes. Since 2012, he has hosted more than 300 road running activities for three consecutive years. With the support of the local government, social organizations, and the local residents, such activities have been combined with local businesses and cuisine to drive this depressed town with a continuous sports culture so that everyone has a sense of community identity and cohesion [60].

3. Use public sector resources in road running: use social resources to solve problems and advocate addressing ecological disputes

Yuantai planned a large-scale road run activity, "Love, Run into the Town", for the first time. The Zhushan Police Station, Zhushan Junior High School, Show Chwan Hospital, Township Office, neighborhood chiefs, and community volunteers provided a lot of manpower support in security maintenance, medical treatment, right of way management, and material supplies [61]. Furthermore, the Nantou County Government commissioned Yuantai to undertake the large-scale "Love, Starlight Fun Run" from Zhushan to Lugu. However, as the running route passed through a firefly habitat, it was opposed by the public. He and his team asked ecological experts to assess whether the route would affect the habitat and then publicized the assessment results of no influence to the public to calm them down [60].

4. Combine road running with local sightseeing: local tours and travel guides enhance popularity through advocating and online-sharing

In "Love, Starlight Fun Run", they arranged the road run at night and provided Zhushan's travel guide on the online registration page, which made passengers interested in staying longer and distributed their energy to different stores. After the activity, they deducted the required costs and donated part of the surplus to the ecological conservation unit [60].

5. Apply large-scale road running planning experience in other places: combine road running with the characteristics of aboriginal tribes and experience the enthusiasm of the aborigines

The practice of local development in which Zhushan participated attracted the attention of local villages and towns. Using the same way of localizing road running, Yuantai assisted the aborigines in Xinyi Township to carry out road running activities. The food and scenery were of outstanding aboriginal characteristics. Runners bring economic income to the tribe with their registration fees and fully feel the brightness and enthusiasm of the aborigines [60].

4.2.2. Practice Environmental Protection for Bamboo Life, and Make Full Use of Network and Social Value Marketing Products

1. Road running expands social capital and business opportunities: obtain the market demand for developing bamboo toothbrushes, conduct social activities, and deeply cultivate the industry at the same time 
Yuantai entrepreneur stated, "Innovation in rural areas is easy to become a bright spot, and continuous activities become a kind of culture, which has gained market resources and interpersonal trust for self-entrepreneurship" (2A03-3). He met the guesthouse owner at the later stage of the road run, where he began developing bamboo toothbrushes because of guesthouse's demand for daily necessities (2A02-5). As everyone recognized the road running activity, the factory staff were willing to break through the technical problems with him and reduce the cost of product research and development and time test (2A02-6). He deemed it easier to face the problem and solve it faster in bamboo-producing areas. So long as he continues to conduct it without fear of difficulties, he believed he could perform it well (2A02-9).

2. Use test product prototypes in online media, bazaars, and in-person: gain experience and feedback to enhance product ease of use

Before the new product was officially launched, Yuantai conducted tests on the network platform many times, assessing the possibility of mass production according to consumer feedback (2A25-3). They also understood users' feelings after use through physical sales bases and enhanced the ease of use through continuous improvement in product materials, processes, and shapes (2A08-2). At the early stage of starting a business, they visited a large number of markets. They would also encounter matchmaking opportunities and gain experience and resources to increase the market share and on-site product experience. Starting a business in villages and towns is exchanged for mileage. "Before developing products, we should first understand the source of everything, know all kinds of media and skills, find the combination of techniques matching modern from the traditional context, think from the user's point of view, and extend the development of products" (2A16-5).

3. Research and development of conceptual products: advocate the social value of ecological environment protection, circular economy, Taiwan culture, and outdoor life through products

The brand value concept of Yuantai is based on environmental protection and sustainable circulation, and it is hoped that products can be decomposed in nature and can be produced and designed in a friendly way using local bamboo materials in Taiwan (2A02-3). In 2015, Yuantai developed the first bamboo toothbrush, created from Zhushan Mengzong bamboo, which was over four years old. It was free of bleaching and preservatives. The bamboo was sterilized by high-temperature cooking and then coated with a layer of nontoxic water-based paint for protection. No matter the product material or service, it has cultural value and is a sustainable concept. For example, the Yuanqi Concave Bean Cup is created out of bamboo waste. Through the proper use of bamboo, these waste materials are given new value without being discarded. The design of bamboo products focuses on social values, such as environmental education, outdoor style, Taiwan culture, and marine life. Together with designers, they have designed a series of thunder carving patterns, including the Taiwan Blue Magpie, Taiwan Black Bear, and Turtle (Figure 6).

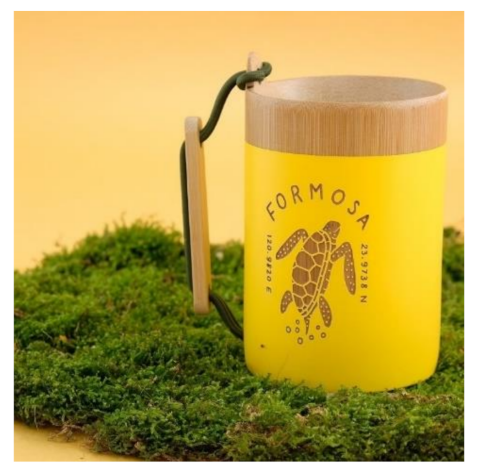

Figure 6. Turtle-patterned bamboo cup. 
In 2018, Yuantai invested in the flyingV fundraising platform with the project of Yuanqi Bamboo Straw - the Weakest Straw on the Earth-, of which the fundraising target was NTD 500,000. The fundraising plan clearly stated the return given to sponsors and donors. If the goal was achieved, Yuantai would start planting arrow bamboo seedlings [65].

4. Practice environmental protection personally: design products with one's own life experience and demonstrate the use of situations and social values

Most of the products developed by Yuantai's founder are based on his own life context. While living a natural, environmentally friendly life and outdoor camping (Figure 7), he brought the products into the situation to take photos and find more possibilities for using bamboo products in day-to-day life (2A13-5, 2A21-2). He often demonstrates the use of bamboo products through the internet and shares photos of product use-brand propaganda, showing a young, fashionable, environmentally friendly, and aesthetic quality life (2A04-2, 2A09-5). He believes that "bamboo products are light, environmental protection, very suitable for outdoor activities. Bamboo forest is the best place for meditation, and life should be so beautiful" [66].

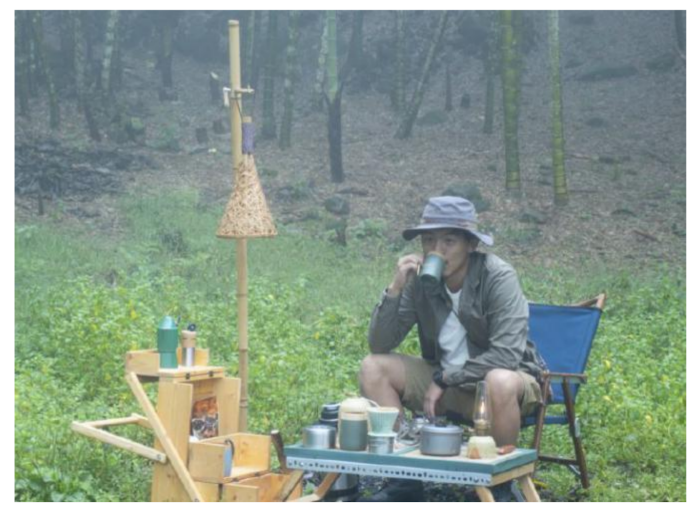

Figure 7. Using bamboo products in bamboo forest.

The founder of Yuantai has been practicing a plastic-free life. After seeing the film of turtle suffering, the idea of developing bamboo straws arose. After starting his business, he met some friends with clean beaches and mountains, hoping to let everyone know how to implement seamless mountains and outdoors. "The Marine Association volunteer group took him to pick up garbage, snorkeled while picking up garbage, and then met turtles" (2A04-3).

5. Enhance the sense of participation in products and services: customization of goods and hand-made experience to enhance ties with users

Yuantai provides customers with customized services for products, such as laser personal slogans on bamboo toothbrushes, hand-painted patterns on bamboo cups, and customized services for joint funds of customers from the guesthouse and different enterprise groups (2B02-3). It cooperated with China Airlines to launch a bamboo toothbrush joint model, and high-end hotels, such as Satoyama-Jujo Hotel in Japan, also customized bamboo toothbrush products [67]. In order to convey a complete life concept by the brand, Yuantai arranged the physical shops in Zhushan into the space form of hand-made workshops in the second half of 2017, "developing experience courses of bamboo toothbrushes and bamboo cups, so that consumers can experience the production of products" (2A04-5).

6. Expand marketing channels with social issues: attract the active attention of mass media and social media, and expand marketing bases to Taiwan and even the world

The marketing channel of Yuantai is mainly the network and dozens of cooperative retail outlets, and most of them promote the brand through TV media interviews or industry speeches. In Yuantai's Facebook fan club, its official brand website, Pinkoi, and other network channels, and beautiful photos of bamboo products, are presented. The knowledge of environmental protection and outdoors is conveyed with strong Yuantai-style 
copywriting to share environmental protection information with consumers through the network, explain the design creativity of products in a Facebook online live broadcast, teach consumers how to maintain products, and let users better understand the characteristics of bamboo products (2A04-4). He stated, "Agents from Germany and Japan see their products such as through FB. There are opportunities for cooperation" (2A17-3). At the same time, after interviews with TV stations and online media, the order volume of products would increase rapidly (2B03-2). They market their brands through physical and virtual network channels, which have been stationed in Singapore, Japan, Malaysia, Europe, etc.

4.2.3. Actively Participate in the Activities Organized by Townway and Carry Out Cooperation between Young Entrepreneurs and Design of Local Activities

1. Actively participate in the Spotlight Meetup activity, link-shared resources, and gather local values

Yuantai has maintained close cooperation with Townway and has become a major local young entrepreneur brand. Group tourists and enterprises brought by Townway often visit the shops and factories of Yuantai and invite him to share his entrepreneurial experience and guide everyone in utilizing bamboo products. When starting a business in a township, the products of start-up brands are of little influence. However, many brand products come together, all coming from one place, forming a force. In turn, the place will be of high value and will be seen by everyone (2A03-2). These brands hatched in the Spotlight Settlement ecological mechanism cooperate without binding each other, growing fastest with each as an organism (2A13-7).

2. Design bamboo container for Taisi Ice Room and design Regional Revitalization Festival

Yuantai is responsible for the container design of the Taisi Ice Room ice cream. Bowls and cups are composed of bamboo materials rich in Zhushan. "I hope tourists will come here to take away the culture of Zhushan, not a bowl of ice. Because bamboo is produced in Zhushan, and the things here are also related to bamboo products. There is no sense of disobedience" (2A30-3). They were invited to attend the Kouba Factory Festival in Japan in October 2017, and were inspired to plan the Zhushan Craft Festival, hoping to connect local craftsmen in series (2A22-4). Therefore, Yuantai cooperated with Townway, mainly responsible for designing industrial activities, and held the Regional Revitalization Festival through multi-party cooperation.

\subsubsection{Evaluation Summary}

The 13 characteristics of the Yuantai correspond to the seven dimensions of social innovation design and sustainability identified in the literature review.

The Yuantai promotes events and aspects of industrial development that uphold social values. This is reflected in the following aspects:

(1) The running activities were organized to satisfy the needs of communities, and spreading awareness through the internet can increase the popularity of the brand;

(2) The implementation of a bamboo-based, environmentally friendly lifestyle and the use of the internet and social values to market products;

(3) Active participation in the organization and involvement in local design efforts.

Because the Yuantai is a young bamboo craft brand, its operations are limited by the following aspects:

(1) The small scale of the local industry. Most brands mainly focus on their own development;

(2) The relatively low level of industrialization. The brand mainly focuses on creating social ideal-based cultural and creative products. Few innovations and breakthroughs have been created through the combination of the bamboo materials and more sophisticated technology. The research and development for material technology requires more time and capital, which creates a challenge; 
(3) The connection between the social values and social capital must be strengthened. Although the operations of the brand require a large amount of energy, social values must still be upheld; this requires collaboration with more enterprises, organizations, and research institutions.

\subsection{Other Three Participating Bamboo Craft Young Entrepreneur Brands: KYOU, La-Boos, and Bamboo-Lai}

Among the bamboo art young entrepreneur brands hatched by Townway, KYOU, La-boos, and Bamboo-Lai are busy with their own brand building on the one hand and cooperating with cooperative exhibitions, travel experiences, and local activities on the other. After returning home to start a business, they used their expertise and work experience to manage family factories, explore industrial operation modes, and focus on the innovation of product and service modes.

4.3.1. Use Professional Work Experience to Locate Entrepreneurial Brands Based on the Situation of Home Factories

1. Use experience in art design to improve bamboo production machines and learn traditional bamboo art

The head of KYOU is the second-generation descendant of the Bamboo Fan Bone Factory. He founded his own brand in 2017 and currently runs his home factory and brand together with his mother. He used what he had learned to redesign the original bamboo strips into bamboo products and held exhibitions of illustrations combined with crafts. $\mathrm{He}$ has worked in bamboo landscaping, graphic design, and product design for seven years. In 2010, he returned to Zhushan because his father was seriously ill and continued producing bamboo strips in his home. He knew many bamboo craftsmen, participated in the Bamboo Art Association of Nantou and Bamboo Art Society of NTCRI to learn traditional bamboo art techniques and joined exhibitions to improve the level of bamboo art creation and painting (3A03-5).

2. Use industrial management experience to rectify family factories and find the direction of brand entrepreneurship

La-boos is a bamboo factory with a 40-year history. It used to be a bamboo chopping board and has been in the bamboo factory in Fujian for more than 10 years. The second generation of bamboo artisan graduated from business management and later worked in many manufacturing companies. In 2012, he returned home to set up his own brand and develop environmentally friendly daily necessities, such as kitchen utensils composed of bamboo glulam. Meanwhile, the head of Bamboo-Lai returned home in June 2016 to start a business. He is the son of a senior bamboo artist in Zhushan. Remarkably, he has four years of hotel management, eight years of aviation, and two years of precision machinery work experience. Upon his return, he improved the spatial layout, machinery, and equipment of the family factory. Further, he used enterprise management strategies to enhance the brand management model, quickly thought about ways to make money, and first used sightseeing elements, DIY, and social networks to solve the crisis of capital income.

4.3.2. KYOU Develops Practical and Craft Bamboo Products, La-Boos Has a Stable Production Line of Bamboo Kitchen Utensils, and Bamboo-Lai Has Modular Bamboo Device Production

1. Research and development process and practical products of KYOU

Since 2011, the head of KYOU has cooperated with the Zhushan Township Office in the visual design of cultural activities for five years, attracting tourists to participate in activities with different themes. At the same time, he managed the production in the home factory, taught the courses of bamboo-weaving technology, and developed practical and technological products such as the combination of bamboo with different materials, illustration, and bamboo technology, forming personal characteristics. At present, there are bamboo products, such as bamboo certificate sets, bamboo postcards, bamboo clocks, 
bamboo storage devices, bamboo lamps, and bamboo key rings, among which the first two products are designed as experience courses (3A03-3).

2. La-boos takes bamboo kitchen utensils and environmental protection products as the core; the division of labor between Fujian and Taiwan factories is clear

The person in charge of La-boos, is familiar with bamboo materials and production processes. He cooperates with designers to jointly develop a variety of bamboo plates with healthy food-sharing concepts for children and adults, constantly upgrade and iterate the products, abide by the brand's core concept, and produce bamboo products with quality assurance for modern families. The business model of their products is stable, with affordable bamboo kitchenware, quality assurance, and a beautiful appearance as the core. The marketing channels include the brand's official website and Eslite, and other physical channels (4A03-4). In product chain management, Fujian factories mainly process rough embryos and semi-finished products of bamboo glulam to reduce costs and unify product quality, while Taiwan factories mainly process fine products and assemble finished products and design (4A04-2).

3. Bamboo-Lai combines the bamboo art experience course with sightseeing and adopts modular bamboo installation

The head of Bamboo-Lai returned to Zhushan and founded the International School of Bamboo Craft. He offered bamboo art experience courses, improved experience price and service quality, digitized experience cost, and hired students of bamboo art masters as teachers (5A01-2). In the business model, the travel agency was matched to form a bamboo craft tour itinerary. They mainly maintained brand management by making bamboo installations. At the same time, he created the bamboo plant project structured and modular and invited local residents with bamboo technology as production assistants to form a subcontracting mode of design and production to improve work efficiency and create job opportunities (5A08-3).

4.3.3. Young Entrepreneurs Met in a Spotlight Meetup Activity and Participated in the Incubation of Brand Mechanisms. The Concept of Resource Integration Affected Their Own Brand Development

1. KYOU cooperates with young entrepreneurs and mainly thinks about its own industrial business model

In 2015, the head of KYOU participated in the Spotlight Meetup activity organized by Townway and thought it could enhance the communication between people from different industries, share their respective problems and experiences, and bring motivation to their entrepreneurship (3A07-5). At the same time, he participated in the young entrepreneurs sharing and experience course of the Townway tour experience, held exhibitions, and entered the shop space together. In August 2017, KYOU, La-boos, and Pure Soap Handmade Soap Store jointly opened the GOODS physical store near Taisi Bus Station, which is the spatial information provided by Townway. In terms of the mode of operation, KYOU is still in the exploratory stage because while rural resources are scarce, few suitable manufacturers are mainly solved through network and product redesign. In brand marketing, most of them are now either undertaking government projects or offering various experience courses for promotion, and products are sold on the Pinkoi platform to position test products in the market (3A15-3).

2. The entrepreneurial concepts of La-boos and Bamboo-Lai are affected, but they need to have the ability to introduce social capital continuously

In 2016, the head of La-boos participated in the Spotlight Meetup activity and fully agreed with the role of Townway as an intermediary series platform. He thought that different micro-entrepreneurial brands had a symbiotic relationship and would have conflicts of interest, while Townway has a neutral role, which could represent local microentrepreneurial brands in publicizing them to the international community (4A07-13). 
He participated in the activity many times, reached the qualification of incubation and upgrading, obtained cooperation resources, participated in the exhibition with young entrepreneurs, and put forward the plan of SBEA.

The founder of Bamboo-Lai also participated in the activities of Townway many times and joined in exhibitions, young entrepreneurs sharing, and the bamboo art experience. As they prepared for their bamboo craft experience courses, Townway interns and project personnel helped test design the course and evaluate its parameters and costs (5A11-5).

\subsubsection{Evaluation Summary}

The seven characteristics of the three youth-led bamboo craft brands, namely, KYOU, La-boos, and Bamboo-Lai, correspond to the seven dimensions of social innovation design and sustainability identified in the literature review. KYOU has focused on the development of bamboo craft products that are both practical and hand-made in small batches by mothers in the community. La-boos manufactures a line of a sustainable, environmentally friendly bamboo kitchen products, with a clear division of labor between the Fujian plant and the Taiwan plant. Bamboo-Lai has adopted a modularized system to manufacture their bamboo products. In terms of social capital utilization, it has mainly cooperated with Townway according to Townway's exhibitions and experiential journeys, which means that the former's level of proactive creativity is low. However, Bamboo-Lai's model is consistent with that of Townway, which prevents segregation. This also necessitates the continuous import of social capital.

\section{Conclusions}

\subsection{The Three Elements: Analyzing Social Problems, Advocacy of Social Values, Proposing Innovative Solutions}

In past industrial models in Zhushan Township, merchants and enterprises focused on their own operations and did not engage in dialogues or cooperation. The township also lacked connection between the local industry and social resources.

The five youth-led bamboo craft brands have upheld their values and maintained sustainability by analyzing social problems, proposing a series of innovative solutions, and realizing social innovation and sustainable development in Zhushan's bamboo craft industry. Their efforts are reflected in three aspects: (1) analyzing social problems; (2) advocacy of social values; (3) proposing innovative solutions. These brands are marketed through the following: (1) collaborations between universities and the public sector, such as the Bamboo Nest Class, Beyoung Garden, Taisi Ice Room, and the revitalization of the Taisi Bus Station; (2) the Spotlight Meetup activity; (3) the shaping of the Zhushan Spotlight Settlement ecological mechanism.

The construction of multipurpose public spaces is key to the social innovation and sustainable development of the Zhushan Township. These spaces can promote dialogues and exchanges, help groups reach a consensus, integrate the resources of multiple external parties, transmit information through various media, and match resources. To sum up, the resource-integrated Townway mainly carries out organizational innovation, industrial innovation, and social value advocacy and practice, of which its social capital mainly comes from the public sector and universities. Furthermore, the sustainable system of enterprises needs to be completed. The other four bamboo craft young entrepreneur brands focus on industrial innovation and participate in social activities. Their industrial chain and brand management mode, being constantly adjusted, remains unclear. In the early stage of Yuantai road running activities and bamboo environmental protection product development, social value drives the implementation of activities and products. Meanwhile, in the later stage, social issues are less involved, and in-depth scientific and technological research and development for bamboo material technology needs to be strengthened. 
5.2. The Three-Stage Model of Zhushan Township: The Internal Collaboration and Enhancement; The Revitalization; The Marketing

The social innovations and sustainable mode created by the five youth-led bamboo craft brands can be divided into the following three stages (Figure 8):

(1) The internal collaboration and enhancement of Zhushan Township. Townway reached a consensus through dialogues and exchanged spaces with the Bamboo Nest Class and the Spotlight Meetup activity to cultivate the youth-led bamboo craft brands Yuantai, KYOU, La-boos, Bamboo-Lai, and other youth-led brands; these brands form the Zhushan Spotlight Settlement incubation;

(2) The revitalization of Zhushan Township. The youth-led organizations created an ecological mechanism for the township by matching local projects, experiential journeys, and local activities initiated by universities, the public sector, and enterprises;

(3) Marketing Zhushan Township. This mechanism can serve as an example of an ecological system that others can learn from. Zhushan Township is marketed through courses cultivating youth-based entrepreneurship, Zhushan exhibitions, documentaries, and the Asia Revitalization Platform. This ecological system can affect the Taiwanese society and the rest of Asia.

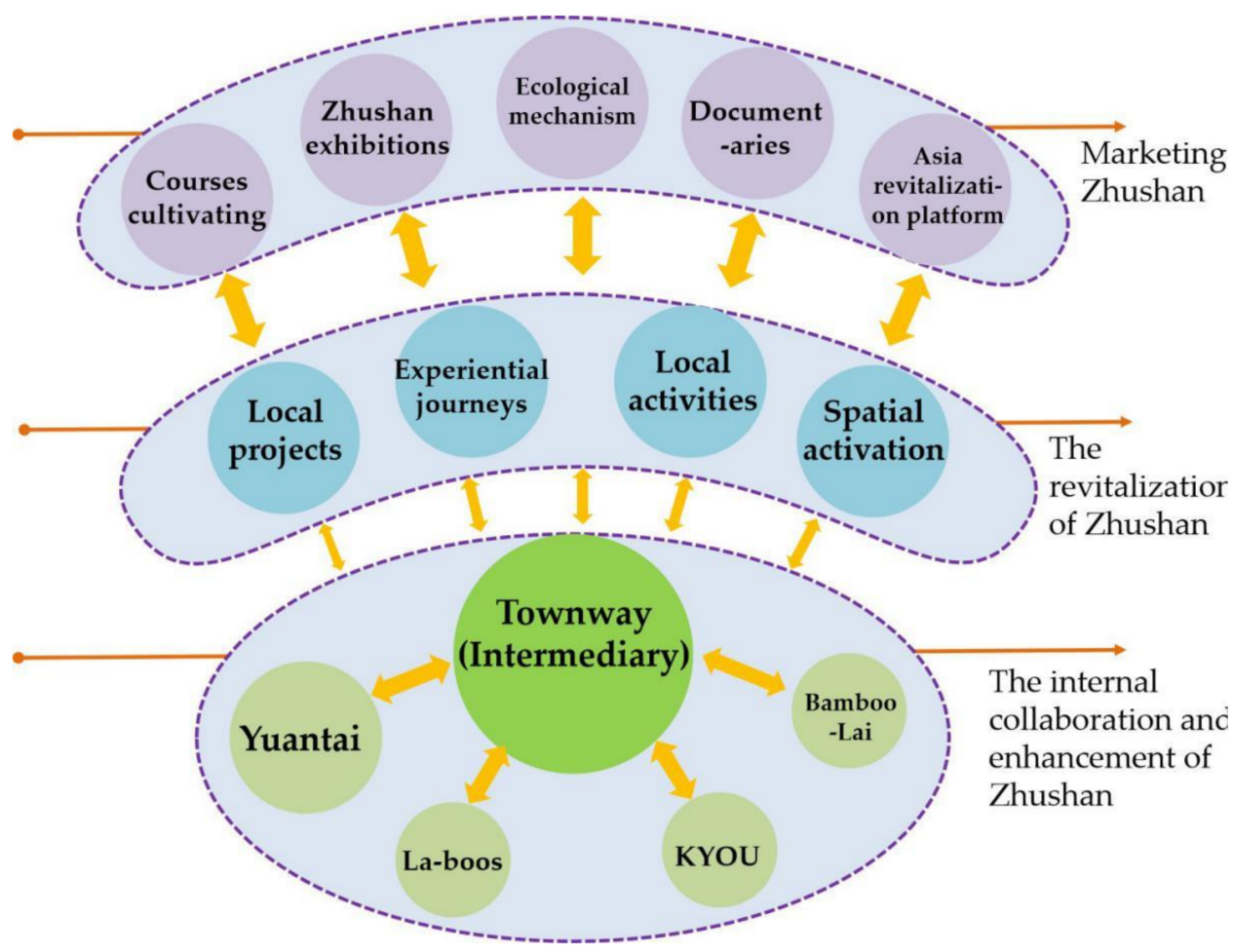

Figure 8. The social innovation design and sustainable mode of these brands.

The stakeholders of this model mainly include cooperative institutions or individuals. While the social influence and connection need to be further expanded, the sustainable development model of the economy and environment must also be enhanced.

5.3. Concerning Social Problems, Social Values, and Social Capital, Creative Solutions Can Be Put Forward through Multiple Participation and New Relevance So as to Practice Sustainable Values and Solve Social Problems

In terms of the development of social innovation design and sustainability, all five youth-led bamboo craft brands have gained social capital by targeting social problems and advocating social values; they used their social capital to solve social problems. In this process, the participation of local industries, enterprises, universities, the public sector, and nonprofit organizations is key to proposing creative solutions through joint deliberation. 
These solutions represent a process of continuous experimentation and implementation; innovation plans are developed through implementation and correction. The participation of these groups can create new relationships, which can lead to the establishment of new organizations, space, and services. Local communities can generate a group dynamic to resolve social problems together. In addition, the participation of a diverse range of groups can promote economic, social, and environmental sustainability (Figure 9).

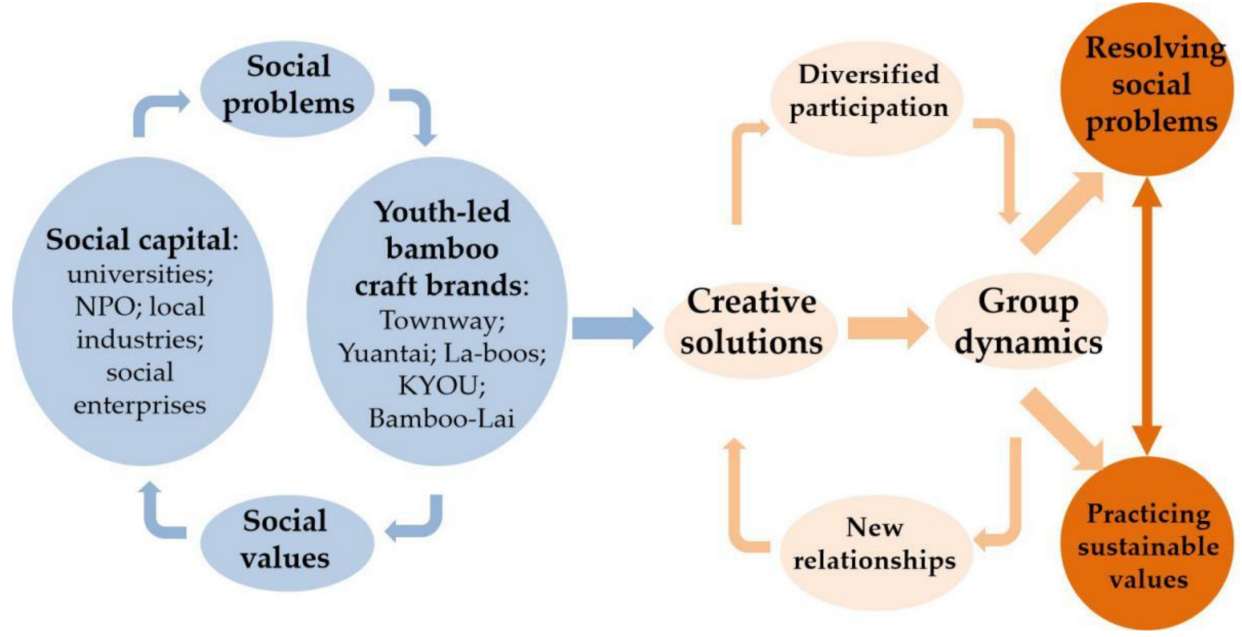

Figure 9. The relationship between social innovation design and sustainability of these brands.

Facing social problems in different periods, Townway integrated micro-social enterprises, constantly strengthened the core concept of locality and social value, encouraged multi-body participation through social capital, formed a new organizational platform, and achieved the sustainable development of the town. The other four micro-enterprises relied on the original family factory resources and network accumulation and used the network and modern marketing means to carry out industrial innovation in product and service models. In particular, Yuantai promoted product demand by practicing social value, which not only enhances local vitality but also achieves the environmental protection life value.

This paper analyzed five young bamboo craft entrepreneur start-up brands that are active in Taiwan's bamboo industry. Townway has been operating for more than 10 years before gradually forming a model of social innovation and sustainable development, which requires long-term efforts. Moreover, the other four micro-enterprises boast social capital accumulation in the early stage of family factories, whose founders have many years of urban work experience before returning home to start businesses. At present, this study only discussed five youth-led bamboo craft brands in Zhushan Township. In the future, a wider social innovation and sustainable development of Zhushan Township, as well as the different social innovation models between Zhushan and other towns in Taiwan, will be explored.

Author Contributions: Y.D. contributed to the conceptual design of the study, data collection, drafting the article, formal analysis, and final approval. S.-H.H. contributed to the conceptual design of the study, supervision of the progress, and final approval. All authors have read and agreed to the published version of the manuscript.

Funding: This research was supported by the Program of Zhejiang Social Science Foundation Youth Project in 2021 (No. 21NDQN286YB), China.

Institutional Review Board Statement: Not applicable.

Informed Consent Statement: Not applicable.

Data Availability Statement: Not applicable. 
Acknowledgments: The authors would like to express sincere thanks to the young entrepreneurs in Zhushan Township, bamboo craftsmen, college teachers and students, and local residents.

Conflicts of Interest: The authors declare no conflict of interest.

\section{References}

1. Nantou Zhushan Radiates New Charm. Available online: https:/ / city.gvm.com.tw/article.html?id=60635 (accessed on 10 March 2020).

2. Wu, Z.W. The Changes of Bamboo Craft Impartation and Education in Zhushan. Master's Thesis, Taipei National University of the Arts School of Culture Resources, Taipei, Taiwan, 2016.

3. Hwang, S.H. On the revitalization policy of Japan's regional cultural industry. Build. Inf. 2005, 6, 59-76.

4. National Taiwan Craft Research Institute (Ed.) Vision-2008 Taiwan Craft Creative Industry; National Taiwan Craft Research Institute: Nantou, Taiwan, 2009; pp. 6-7.

5. UNESCO. Shaping the Future We Want. UN Decade of Education for Sustainable Development (2005-2014). 2014. Available online: http:/ / unesdoc.unesco.org/images/0023/002301/230171e.pdf (accessed on 14 June 2018).

6. Chen, H.P. Turn Around Inferior Position: Inject New Living Water for Bamboo Industry. Harvest 2021, 71, 18-23.

7. Zen, Y.L. Bamboo Use of Innovative Strength: With a Variety of Bamboo Products to Expand the New Blue Ocean. Harvest 2021, 71, 62-69.

8. Borowski, P.F. Innovation Strategy on the Example of Companies Using Bamboo. J. Innov. Entrep. 2020, $10,1-17$.

9. Kao, Y.F.; Hwang, S.H. Research on the Cultivation of Bamboo Crafts Talents-Taking Nantou County as an Example. In Multiple New Cultures, Cross-Domain Innovation Opportunities-A New Humanistic Vision of Taiwan's Emerging Scholars; Chien-Chiu, S., Ed.; Wan Juan Lou Books: Taibei, Taiwan, 2016; pp. 120-142.

10. Ho, Z.-L.; Xu, G.-P. Paper to Innovation: Surplus Bamboo Materials Used in Special Paper Series Product Development. Res. Bull. 2020, 27, 3-5.

11. Yang, J.H. Looking Forward to Sustainable Management of Bamboo Forest in Taiwan: Analysis of Bamboo Industry Changes and Bamboo Characteristics by Chen Cai-hui, Bamboo Expert. Harvest 2021, 71, 25-31.

12. Chang, J.Y. Exploring the Entrepreneurship Ecosystem for a Social Enterprise: A Case Study of Taiwan Townway. Master's Thesis, Institute of Cultural and Creative Industries, National Kaohsiung University of Science and Technology, Kaohsiung, Taiwan, 2020.

13. Nuan, H.Y. The Management and Development of Local Cultural and Creative Industries-A Case Study of "Townway" in Zhushan, Nantou. Master's Thesis, Institute of Science and Technology Management, National Chiao Tung University, Hsinchu, Taiwan, 2016.

14. Wu, H.-L. Redefining Life Winners: Values of Contribution to the Society and Place. J. Educ. Res. 2015, 249, 31-44.

15. Shaw, E. Marketing in the social enterprise context: Is it entrepreneurial? Qual. Mark. Res. Int. J. 2004, 7, 194-205. [CrossRef]

16. OECD. The Non-Profit Sector in a Changing Economy; OECD: Paris, France, 2003.

17. Hwang, Y.S.; Wang, D.; Chang, S.W. Innovative Innovation: How Social Innovation Models Lead the Era of Crowd-Creation; Zhejiang People's Publishing House: Hangzhou, China, 2016; pp. 15-20.

18. Schumann, P.A.; Prestwood, D.; Tong, A.; Vanston, J. Innovate: Straight Path to Quality, Customer Delight, and Competitive Advantage; McGraw Hill: New York, NY, USA, 1994.

19. Brooks, H. Social and Technological Innovation; Lundstedt, E., Colglazier, W., Jr., Eds.; Managing Innovation; Pergamon Press: Elmsford, NY, USA, 1982; pp. 9-10.

20. Mulgan, G.; Tucker, S.; Ali, R.; Sanders, B. Social Innovation: What it Is, Why it Matters and How it Can Be Accelerated; University of Oxford: Oxford, UK, 2007.

21. Phills, J.A.; Deiglmeier, K.; Miller, D.T. Rediscovering social innovation. Stanf. Soc. Innov. Rev. 2008, 6, $34-43$.

22. Oosterlynck, S.; Novy, A.; Kazepov, Y. Local Social Innovation to Combat Poverty and Exclusion; Policy Press, University of Bristol: Bristol, UK, 2020; pp. 5-28.

23. Liu, B. Corporate Social Innovation: A New Paradigm of Corporate Innovation. Technol. Prog. Countermeas. 2011, $28,87-92$.

24. Fagerberg, J.; Mowery, D.; Nelson, R. The Oxford Handbook of Innovation; Oxford University Press: Oxford, UK, 2005; pp. 102-130.

25. The Analysis of Social Innovations as Social Practice. Available online: https://www.academia.edu/18385585/The_Analysis_of_ Social_Innovations_as_Social_Practice (accessed on 5 March 2021).

26. Social Innovatio: Concepts, Research Fields and International Trends. Available online: https://www.asprea.org/imagenes/IM O\%20Trendstudie_Howaldt_englisch_Final\%20ds.pdf (accessed on 8 October 2020).

27. Putnam, R.D. Tuning In, Tuning Out: The Strange Disappearance of Social Capital in America. Political Sci. Politics 1995, 28, 664-683. [CrossRef]

28. Onyx, J.; Bullen, P. Measuring social capital in five communities. J. Appl. Behav. Sci. 2000, 36, 23-42. [CrossRef]

29. Patuzzi, L. European Cities on the Front Line: New and Emerging Governance Models for Migrant Inclusion; Migration Policy Institute Europe and International Organization for Migration: Brussels, Belgium; Geneva, Switzerland, 2020; pp. 85-102.

30. Papanek, V.; Fuller, R.B. Design for the Real World; Thames and Hudson: London, UK, 1972; pp. 38-62.

31. Brown, T.; Wyatt, J. Design Thinking for Social Innovation. Stanf. Soc. Innov. Rev. 2010, 8, 28-35. [CrossRef] 
32. The Sociology Imagination from Design to Social Design. Available online: http://www.seinsights.asia/story/257/13/1590 (accessed on 23 April 2016).

33. Manzini, E. Design, When Everybody Design: An Introduction to Design for Social Innovation; MIT Press: Cambridge, MA, USA; London, UK, 2015; pp. 76-80.

34. Manzini, E.; Rizzo, F. Small Projects/Large Changes: Participatory Design as an Open Participated Process. Codesign 2011, 7, 199-215. [CrossRef]

35. Leadbeater, C. We-Think; Profile Books: London, UK, 2008; pp. 122-130.

36. Ji, T.; Pan, Y. Community and Network Based Design and Social Innovation: From UCD to CCD. Zhuangshi 2012, 12, 109-111.

37. Zhao, X. Order Changes and Value Reconstruction of Rural Culture. Master's Thesis, Hebei Normal University, Shijiazhuang, China, 2012.

38. Zhang, L.; Lin, X.; Yang, G. Cross-culture Thinking in Sustainable Service Design of Social Innovation: Case Comparison between Milan, IT and Wuxi, China. Creat. Des. 2015, 3, 66-70.

39. Ran, X.M. Thinking and Suggestion for the Revitalization of Rural Culture. Think Tank Era 2019, 3, 24.

40. Li, X.L.; Gong, M.S.; Xiao, D.J. Study on Service Design for Sustainable Lifestyle in Mobile Internet Society. Design 2015, 22, 122-123.

41. Gostoli, Y. Coronavirus in Italy: Solidarity in the Time of Disease; Deutsche Welle: Bonn, Germany, 2020.

42. United Nations Development Programme (UNDP). Transitioning from the MDGs to the SDGs; UNDP: New York, NY, USA, 2015.

43. United Nations. Transforming Our World: The 2030 Agenda for Sustainable Development. Available online: https://sdgs.un.or g/2030agenda (accessed on 3 February 2021).

44. Kuang, H.S. A preliminary Study on the Planning, Design and Restoration Guidelines for the Aborigines' Sustainable Villages in Taiwan. Tunghai J. 2004, 45, 33-62.

45. Corsini, L.; Moultrie, J. Design for social sustainability: Using digital fabrication in the humanitarian and development sector. Sustainability 2019, 11, 3562. [CrossRef]

46. Liu, S.H. Study on the Construction Feasibility of Citizen Participation of Low-carbon City. J. Natl. Taichung Univ. 2015, 2, 135-163.

47. Sun, C.-G.; Zhang, Z.-Q. Analysis on Current Situation and Influence Factors of Community Residents' Participation during the Process of Low-Carbon City Construction: On the Basis of an Empirical Investigation in Chengyang District, Qingdao, Mainland China. J. Urbanol. 2015, 1, 29-62.

48. Wang, G.Y. Sustainable Development and Technological Innovation. Development 2007, 12, 19-20.

49. Yu, S.H.; Ruan, R.F. The Experience of International Low Carbon Community Public Participation. Beijing City Plan. Constr. 2011, 5, 74-76.

50. Ji, T.; Yang, Y.Y.; Zhao, J.H. Regional Intangible Culture and Native Design System. J. Hunan Univ. $2009,1,143$.

51. Chang, W.S. The Second Phase Report of Nantou County Design and Reversal of Local Creation and Entrusted Professional Services; National Development Council, Nantou County Government: Nantou, Taiwan, 2018.

52. Ryan. DESIS Theme Cluster Distributed and Open Production. Climate Change and Ecodesign (Part II). Available online: http:/ / design-network.org/dop (accessed on 5 September 2014).

53. Biggs, C.T.B.; Ryan, C.J.R.; Wiseman, J.R. Distributed Systems: A Design Model for Sustainable and Resilient Infrastructure. Veil 2014, 3, 10-15.

54. Manzini, E. Error-Friendliness: How to Design Resilient Sociotechnical Systems. In Architecture in an Age of Depleting Resources, Architectural Design Profile; Goofbun, J., Ed.; Wiley: Hoboken, NJ, USA, 2012; p. 218.

55. Walker, B.; Salt, D. Resilience Thinking: Sustaining Ecosystems and People in a Changing World; Island Press: Washington, DC, USA, 2006.

56. Maxwell, J.A. Qualitative Research Design: An Interactive Approach; Sage Publications: Thousand Oaks, CA, USA, 2012.

57. Qi, L.; Lin, B.X. Review of Grounded Theory Research Methods. In Qualitative Research Methods and Data Analysis; Institute of Education and Social Sciences, Nanhua University: Chiayi, Taiwan, 2005; pp. 268-305.

58. Chang, S.Y. Research on user ordering behavior based on KJ analysis. Art Apprec. 2019, 3, 53-54.

59. Chen, S.B. The key opportunity for the development of local entrepreneurship-social enterprise power to drive innovation. Taiwan Econ. Res. Mon. 2019, 42, 56.

60. Zheng, J.T. The Model of Townway's Social Innovation. Master's Thesis, Department of Business Administration, National Taiwan University of Science and Technology, Taipei, Taiwan, 2014.

61. Ho, P.J. There Is a Style of Life, Called a Small Town: A Courtyard in the Sky: It Flips the Dreams, Beliefs and Values of a Place; Seeing the Culture of the World: Taipei, Taiwan, 2015; pp. 105-285.

62. Cluster Innovation of Small Town Cultural and Creative. Available online: https://www.youtube.com/watch?v=fJQvyZLn0yo\& $\mathrm{t}=6 \mathrm{~s}$ (accessed on 5 October 2017).

63. The Town of Wenchuang Is Committed to Building Zhushan into a Cultural and Creative Silicon Valley-Small Business Innovation Research and Development Plan. Available online: https://www.sbir.org.tw/download/page/\%E5\%B0\%8F\%E9\%8E\%AE\%E6\% 96\%87\%E5\%89\%B5.pdf (accessed on 21 October 2019).

64. Townway Co., Ltd. Light up the Road to Town Revival. Available online: https://udesign.udnfunlife.com/mall/cus/gbr/Cc1g 03.do?dc_btn_0=Func_Read_Design_Article\&dc_xuid_0=36 (accessed on 20 June 2018). 
65. Ho, P.J.; Yang, L.L. What Kind of Town Do You Want to Live in? He Peijun's Nine Views on Creation; Seeing the Culture of the World: Taipei, Taiwan, 2020; pp. 120-265.

66. Yuantai Bamboo Takes over the Father's Bamboo Factory and Brings Back the First Bamboo Toothbrush Made in Taiwan. Available online: https:/ /www.triptaiwan.com/2019/06/11/ (accessed on 15 June 2020).

67. The Transformation of Traditional Industries. Available online: https://www.sinchew.com.my/content/content_2301355.html (accessed on 7 June 2021). 